\title{
Impact of Some Economic Variables on the Real Gross Domestic Product of Nigeria
}

\author{
Ademuyiwa, J.A. ${ }^{1}$, Adetunji, A.A. ${ }^{2}$ \\ ${ }^{1,2}$ Department of Statistics, Federal Polytechnic, Ile-Oluji, Ondo State, Nigeria \\ adeadetunji@fedpolel.edu.ng
}

\begin{abstract}
The influences of External Debt Service (EDS), External Debt Stock (EDSt), Government Expenditure (GE), Inflation Rate (InfR), Interest Rate (IntR) and Exchange Rate (ExR) of Nigeria on the Real Gross Domestic Product (RGDP) are examined. Results of the analysis using Stepwise Regression (Backward Elimination and Forward Selection) reveals that GE, EDS, and IntR have positive significant contributions to the RGDP of the country compared to other variables considered.
\end{abstract}

Keywords: External debt; government expenditure; inflation rate; interest rate; exchange rate; real GDP; stepwise regression.

\section{Introduction}

The real Gross Domestic Product (real GDP) of any country is a measure of the value of economic output adjusted for price changes (inflation/deflation) in that country. It is the sum of the consumer spending, the investment made by industry, the excess of exports over imports, and the government spending. When an economy is going through a persistent inflation, the GDP increases, this does not actually reflect the true growth in an economy. Hence, the rate of inflation must be subtracted from the GDP to get the real growth percentage, called the real GDP.

While the nominal GDP is the market value of all final goods produced in a geographical region, usually a country, real GDP accounts for price changes that may occur due to inflation. If prices of commodities change from one period to the next but actual output does not, nominal GDP would also change. To adjust for changes in price, real GDP is calculated using prices from a specific year (the base year) in comparison to the year of interest, this allows real GDP to accurately measure changes in output. The GDP of any country plays an important role in comparing her economic activities with others, hence, the need for the identifying various variables that contributes significantly to the real GDP for purposeful prediction. This paper therefore examines the joint contribution of some economic variables on the real GDP of Nigeria using data as that span 30 years from 1986 to 2015.

Countries indulge in debt to boost economic and reduce poverty level such that it does not suffer from macro-economic instability. Nigeria's debt burden is a complex interrelated problem with efforts on external debt management through measures like debt rescheduling, debt forgiveness or cancellation and so on having little or no impact. Debt burden in Nigeria can be traced to the early 1980s and a sizeable chunk of the nation's foreign earning has been appended on debt servicing over the years. This has caused some setback in the nation's development. The magnitude of the debt and its associated adverse effect has become concern to the government at different levels. Unprecedented debt crises is evident in the inability of various state governments to pay workers. Researches (Okoye, Modebe, Adedayo \& Evbuomwan, 2017; Sulaiman \& Azeez, 2012; Ayadi \& Ayadi, 2008; Ajayi \& Oke, 2012, Zaman \& Arslan, 2014) have shown evidences of significant correlation between external debt and economic growth. Hence, the contribution of external debt to a country's economic growth is highly pertinent. Often times, developing economies with insufficient capital for infrastructural developments acquire external debt to supplement domestic savings. Since most 
of the foreign creditors charge lower interest compared to domestic market, nations usually prefer the latter but a major problem that has bedeviling developing nations is that most of the money borrowed usually end up in private pockets at the expense of the entire nations. The debt, if properly utilized, is expected to help the debtor country's economy by producing a multiplier effect which leads to increased employment, adequate infrastructural base, a larger export market, improved exchange rate and favorable terms of trade. But, this has never been the case in Nigeria and several other Sub-Saharan African countries (SSA). Apart from the fact that external debt had been badly expended in these countries, the management of the debt by way of service payment, which is usually in foreign exchange, has also affected their macroeconomic performance. The history of Nigeria's huge debts can hardly be separated from its decades of misrule and the continued recklessness of its rulers.

Researches relating the external debt to the development of different nations are numerous. Ayadi \& Ayadi (2008) examined the impact of the external debt, with its servicing requirements on economic growth of the Nigerian and South African economies, using both Ordinary Least Square (OLS) and Generalized Least Square (GLS) methods, it was revealed that debt and its servicing requirement has a negative impact of on the economic growth. Study by (Ogunmuyiwa, 2011) as well showed that there is no causality between the external debt and economic growth in Nigeria. In the last few years, debt service had been taking at least $20 \%$ of the annual budget of the country. The country's economy is under perpetual pressure as a result of debt servicing and this has had a significant adverse effect on the growth process, (Adepoju, Salau \& Obayelu, 2007; Audu, 2004; and Mohammed, 2005). Outside the shore of Nigeria researchers (Malik, Hayat, \& Hayat 2010; Hammed, 2008; and Fosu, 2007) have found similar trend on the effect of external debt on economic growth.

Unlike Classical theorist that see no relationship between government spending and economic growth, the Keynesians assert that more government spending have positive impact on the GDP. Fouladi, (2010) reported the effect of investment expenditure by the government is a function of where and how they are spent on the economy. Expansion in Fiscal budget had been reported to promote economic growth (Barro, 1990; Komain, 2007), supporting the Keynesian's theory. A negative relationship was reported for government expenditure and economic growth (Al-Gifari, 2015) when the expenditure was disaggregated in to operating expenses and development expenditure. A study on Nigeria's government expenditure (Nurudeen \& Usman, 2010) found that both capital and recurrent expenditures have negative effect on the economic growth but expenditure on transport and communication increases the economy. Another paper (Jelilov \& Musa, 2016) found a positive and significant relationship between economic growth and government expenditure. Researches opined that increases in inflation rate reduces economic growth (Hakeem, Rasaki, \& Oyelekan, 2015) but if production environment is made conducive enough, output level and productivity will be increased and thereby reduces inflation. Mehari \& Wondafrash (2008) revealed that increase in money supply in an economy has direct effect on inflation.

Interest rates is very important for efficient distribution of economic resources that may affect the economic growth of a country (Fatoumata, 2017). Usually, high interest rate promotes saving culture and the reverse promotes borrowing. An economy is stimulated for growth when the interest rates is decreased. Also, when there is a reasonably high interest rate, there is tendency for the economic activities to be sluggish.

The exchange rate of country's currency is the amount of such currency that exchanges for currency of another country, most of the world economies had been dollarized and hence, 
the America dollar has become standard to which most of the currencies are compared. Its impact on the economic output of different countries had been well documented in literatures. Morley (1992) found that economic output is reduced when there is depreciation in the real exchange rate. A relationship was also discovered by (Ndung'u, 1997) between inflation rate and exchange rate. Copelman \& Wermer (1996) discovered a negative and significant relationship between exchange rate depreciation and economic output.

In explaining various macro-economic variable highlighted above, diverse models had been utilized and compared. This research aims at observing the joint effect of these variables on the real GDP of Nigeria using the stepwise regression technique.

\section{Research Method}

A multiple regression model is a technique which allows for prediction of one variable given several other. Researchers use the term "independent variables" to identify those variables that they think will influence some other called the dependent variable. But the term "predictor variables" are mostly used for those variables that may be useful in predicting the scores on another variable call the "criterion variable". Extending the concepts developed in dealing with simple linear regression to several explanatory variables, the regression equation in such a case becomes:

$\hat{Y}=\beta_{0}+\beta_{1} X_{1}+\cdots+\beta_{n} X_{n}$

Where, $\hat{Y}$ is the predicted $Y$ (dependent variable), $X_{1}, X_{2} \ldots X_{n}$ are independent variables, $\beta_{0}$ is the intercept and $\beta_{1}, \ldots \beta_{\mathrm{n}}$ are the regression coefficients.

The regression coefficient $\beta$ is given by:

$\mathrm{b}=\left(\mathrm{X}^{\mathrm{I} X}\right)^{-\mathrm{I}} \mathrm{X}^{\mathrm{I}} \mathrm{Y}$

Stepwise Regression includes regression models where the choice of predictive variables is carried out by an automatic procedure. The process usually takes the form of a sequence of t-tests or F-tests or t-tests, though other techniques such as adjusted R-square, Akaike information criterion, Bayesian information criterion, or false discovery rate are possible. Its main approaches are:

a. Backward Elimination

This involves starting the model with all competing variables of a given model comparison criterion and step-wisely deleting the variables (if any) that brings an improvement in the model, and continually repeating this process until no further improvement.

Given the model with all possible covariates as:

$Y=\beta_{0}+\beta_{1} X_{1}+\cdots+\beta_{n} X_{n}+\varepsilon$

Step 1:

The original model is set to be (iii)

Then, the following $(n-1)$ tests are carried out, $H_{o j}:=\beta_{j}=0, j=1,2, \ldots, n-1$

The lowest partial F-test value $F_{l}$ corresponding to $H_{o j}:=\beta_{j}=0$ or t-test value $t_{l}$ is compared with the pre-selected significance values $F_{0}$ and $t_{0}$. Either Step $2 \mathrm{a}$ or $2 \mathrm{~b}$ is then taken.

Step 2a:

$X_{l}$ is be deleted if $F_{l}<F_{0}$ or $t_{l}<t_{0}$, and the new model is:

$Y=\beta_{0}+\beta_{1} X_{1}+\cdots+\beta_{l-1} X_{l-1}+\beta_{l+1} X_{l+1}+\cdots+\beta_{n-1} X_{n-1}+\varepsilon$ 
Go back to step 1 .

Step 2b:

If $F_{l}>F_{0}$ or $t_{l}>t_{0}$, the original model is chosen.

b. Forward Selection

This procedure starts with no variable in the model, testing the addition of each variable using a specific model selection criterion for comparison and repeating the process until there is no further possible improvement.

Step 1:

The original model is $\quad Y=\beta_{0}+\varepsilon$. There are $n-1$ covariates, $X_{1}, X_{2}, \ldots, X_{n-1}$.

Select the variable most correlated to $Y$, say $X_{i l}$, based on the correlation coefficient. Fit the model $Y=\beta_{0}+\beta_{i_{1}} X_{i_{1}}+\varepsilon$ and check if $X_{i l}$ is significant. If not, then $Y=\beta_{0}+\varepsilon$ is the best model. Otherwise, the new original model is: $Y=\beta_{0}+\beta_{i_{1}} X_{i_{1}}+\varepsilon$ and go to step 2. Step 2:

Examine the partial correlation $r_{Y X_{j} X_{i 1}}, j \neq i_{1}$

Find the covariate $X_{i 2}$ with largest partial correlation $r_{Y X_{j} * X_{i 1}}$, then the model:

$Y=\beta_{0}+\beta_{i_{1}} X_{i_{1}}++\beta_{i_{2}} X_{i_{2}}+\varepsilon$ and obtain partial F-value, $F_{i_{1}}$ corresponding to $H_{0}: \beta_{i_{1}}=$ 0 and $F_{i 2}$ corresponding to $H_{0}: \beta_{i_{2}}=0$. Go to step 3 .

Step 3:

Compare the smaller partial F-value, $F_{l}$ (one of $F_{i_{1}}$ and $F_{i_{2}}$ ) with the pre-selected significance $F_{0}$ value. There are two possibilities:

- If $F_{l}<F_{0}$, then delete the covariate corresponding to $F_{l}$. Go back to Step 2

Note that if $F_{l}=F_{i_{2}}$, then examine the partial correlation $r_{Y X_{j} * X_{i 1}}, j \neq i_{1} \neq i_{2}$

- If $F_{l}>F_{0}$, then $Y=\beta_{0}+\beta_{i_{1}} X_{i_{1}}++\beta_{i_{2}} X_{i_{2}}+\varepsilon$ is the new model.

Go back to Step 2, but now examine the partial correlation $r_{Y X_{j} *\left(X_{i_{1}}, X_{i_{2}}\right)}, j \neq i_{1} \neq i_{2}$

The process stops when there is no variable in the new model that can be removed.

\section{Discussion}

With the independent variable of Real Gross Domestic Product (RGDP) and the explanatory variables are External Debt Stock (EDSt), inflation rate (InfR), Exchange Rate (ExR), External Debt Service (EDS), Government Expenditure (GE) and Interest rate (IntR), the general model to be obtained is:

RGDP $=\beta_{0}+\beta_{1}$ EDSt $+\beta_{2}$ InfR $+\beta_{3}$ ExR $+\beta_{4}$ EDS $+\beta_{5} \mathrm{GE}+\beta_{6}$ IntR,

Table 1. Table showing the Variables Entered (Forward Selection)

\begin{tabular}{|c|l|l|}
\hline Model & Variables Entered & Method \\
\hline 1 & GE & $\begin{array}{l}\text { Stepwise Criteria: } \\
\text { The probability of } F \text { to enter } \leq 0.050, \\
\text { The probability of } F \text { to remove } \geq 0.100 .\end{array}$ \\
\hline
\end{tabular}




\begin{tabular}{|l|l|l|}
\hline 2 & EDS & $\begin{array}{l}\text { Stepwise Criteria: } \\
\text { The probability of } F \text { to enter } \leq 0.050, \\
\text { The probability of } F \text { to remove } \geq 0.100 .\end{array}$ \\
\hline 3 & IntR & $\begin{array}{l}\text { Stepwise Criteria: } \\
\text { The probability of } F \text { to enter } \leq 0.050, \\
\text { The probability of } F \text { to remove } \geq 0.100 .\end{array}$ \\
\hline
\end{tabular}

The table above shows the forward selection of the variables of interest. Model uses only GE to explain the RGDP i.e. $\widehat{\text { RGDP }}=\beta_{0}+\beta_{1}$ GE. The second model used both GE and EDS in explaining the RGDP ( $\widehat{\mathrm{RGDP}}=\beta_{0}+\beta_{1} \mathrm{GE}+\beta_{2} \mathrm{EDS}$ ), while the third model adds the interest rate to the model ( $\widehat{\mathrm{RGDP}}=\beta_{0}+\beta_{1} \mathrm{GE}+\beta_{2} \mathrm{EDS}+\beta_{3}$ IntR).

Table 2. Model Summary

\begin{tabular}{|c|c|c|c|}
\hline Model & R Square & Adjusted R Square & Std. Error of the Estimate \\
\hline 1 & 0.943 & 0.941 & 42533.99940 \\
\hline 2 & 0.961 & 0.958 & 36036.69494 \\
\hline 3 & 0.970 & 0.967 & 32119.91133 \\
\hline
\end{tabular}

With the highest coefficient of determination and the adjusted $\mathrm{R}^{2}$ of 0.970 and 0.967 respectively and the least standard error of the estimate, table 2 shows that the model 3 $\left(\widehat{\mathrm{RGDP}}=\beta_{0}+\beta_{1} \mathrm{GE}+\beta_{2} \mathrm{EDS}+\beta_{3} \mathrm{IntR}\right)$ gives the best explanation to the variation observed in the RGDP of Nigeria.

Table 3. ANOVA Table

\begin{tabular}{||l|l|r|r|r|l|}
\hline \multicolumn{2}{|l}{ Model } & Sum of Squares & df & Mean Square & \multirow{2}{*}{ Sig. } \\
\hline \multirow{3}{*}{1} & Regression & 844185934949.500 & 1 & 844185934949.500 & \\
\cline { 2 - 6 } & Residual & 50655950943.835 & 28 & 1809141105.137 & \multirow{3}{*}{0.000} \\
\cline { 2 - 6 } & Total & 894841885893.310 & 29 & & \\
\hline \multirow{3}{*}{2} & Regression & 859778514576.120 & 2 & 429889257288.100 & \\
\cline { 2 - 5 } & Residual & 35063371317.190 & 27 & 1298643382.118 & \multirow{3}{*}{0.000} \\
\cline { 2 - 5 } & Total & 894841885893.31 & 29 & & \\
\hline \multirow{3}{*}{3} & Regression & 868017979598.420 & 3 & 289339326532.800 & \multirow{3}{*}{0.000} \\
\cline { 2 - 5 } & Residual & 26823906294.896 & 26 & 1031688703.649 & \\
\cline { 2 - 5 } & Total & 894841885893.310 & 29 & & \\
\hline
\end{tabular}

Table 3 indicates that all the three models under comparison are significant since their respective P-values (0.000) is less than the level of significance $(\alpha=0.05)$.

Table 4. Regression Coefficients

\begin{tabular}{|l|l|r|r|l|l|}
\hline \multirow{2}{*}{\multicolumn{2}{|l|}{ Model }} & \multicolumn{2}{|c|}{ Unstandardized Coefficients } & Standardized Coefficients & \multirow{2}{*}{ Sig. } \\
\cline { 3 - 6 } & B & Std. Error & Beta & \\
\hline \multirow{2}{*}{1} & (Constant) & 233811.776 & 9697.568 & & 0.000 \\
\cline { 2 - 6 } & GE & 0.147 & 0.007 & & 0.000 \\
\hline 2 & (Constant) & 227216.883 & 8433.768 & & 0.000 \\
\hline
\end{tabular}




\begin{tabular}{|l|l|r|r|r|r|}
\hline \multirow{3}{*}{3} & GE & 0.140 & 0.006 & 0.926 & 0.000 \\
\hline \multirow{4}{*}{3} & EDS & 0.096 & 0.028 & 0.140 & 0.002 \\
\cline { 2 - 6 } & (Constant) & 177096.813 & 19262.525 & & 0.000 \\
\cline { 2 - 6 } & GE & 0.141 & 0.005 & 0.929 & 0.000 \\
\cline { 2 - 6 } & EDS & 0.093 & 0.025 & 0.135 & 0.001 \\
\cline { 2 - 6 } & IntR & 2729.815 & 965.958 & 0.096 & 0.009 \\
\hline
\end{tabular}

The models obtained from the analysis are:

Model 1: $\widehat{\mathrm{RGDP}}=233811.776+0.147 \mathrm{GE}$

Model 2: $\widehat{\mathrm{RGDP}}=227216.883+0.140 \mathrm{GE}+0.096 \mathrm{EDS}$

Model 3: $\widehat{\mathrm{RGDP}}=177096.813+0.141 \mathrm{GE}+0.093 \mathrm{EDS}+2729.815 \mathrm{IntR}$

All the regression coefficients are significant, supporting the observation from table 3.

Table 6. Table of Excluded Variables (Backward Elimination)

\begin{tabular}{|l|l|r|l|r|r|}
\hline \multirow{2}{*}{ Model } & \multirow{2}{*}{ Beta In } & Sig. & Partial Correlation & Collinearity Statistics \\
\cline { 4 - 6 } & & & & Tolerance \\
\hline \multirow{4}{*}{1} & EDSt & 0.116 & 0.009 & 0.475 & 0.952 \\
\cline { 2 - 6 } & InfR & 0.013 & 0.799 & 0.050 & 0.886 \\
\cline { 2 - 6 } & ExR & 0.256 & 0.002 & 0.554 & 0.266 \\
\cline { 2 - 6 } & EDS & 0.140 & 0.002 & 0.555 & 0.894 \\
\cline { 2 - 6 } & IntR & 0.102 & 0.020 & 0.430 & 1.000 \\
\hline \multirow{4}{*}{2} & EDSt & 0.079 & 0.056 & 0.366 & 0.841 \\
\cline { 2 - 6 } & InfR & 0.025 & 0.552 & 0.117 & 0.879 \\
\cline { 2 - 6 } & ExR & 0.169 & 0.049 & 0.376 & 0.195 \\
\cline { 2 - 6 } & IntR & 0.096 & 0.009 & 0.485 & 0.997 \\
\hline \multirow{3}{*}{3} & EDSt & 0.056 & 0.149 & 0.286 & 0.786 \\
\cline { 2 - 6 } & InfR & -0.026 & 0.534 & -0.125 & 0.706 \\
\cline { 2 - 5 } & ExR & 0.118 & 0.145 & 0.288 & 0.180 \\
\hline
\end{tabular}

From the table of excluded variables, five predictor variables (EDSt, InfR, ExR, EDS, and IntR) do not enter into the regression equation at step 1. The implication of this is that only GE is chosen for the first step of stepwise regression [see table 1]. Both GE and EDS are considered for step 2 while the remaining four variables (EDSt, InfR, IntR, and ExR) are excluded from the model. In the third step, EDSt, InfR, and ExR are removed from the model. This implies that all excluded variables are not fit for the prediction of RGDP since their respective probability values are exceed the $\alpha$-value (0.05).

\section{Conclusion}

In examining the contributions of some economic variables into the real gross domestic product (RGDP) of Nigeria, this research uses stepwise regression (forward selection and backward elimination) and the results shows that the three best predictor variables for the RGDP are (i) Government Expenditure (GE), (ii) Interest Rate (IntR) and (iii) External Debt Service (EDS). GE enters into the model at the first step; EDS enters at the second step while the IntR enters at the third stage. The other three predictor variables, External Debt Stock (EDSt), Inflation Rate (InfR), and Exchange Rate (ExR) do not enter into the regression 
equation. The implication of this is that any change among the contributory predictors will affect the RGDP of the country. However, any of the excluded variables (External Debt Stock, Inflation Rate, and Exchange Rate) are insignificant to the change in the real GDP of the country.

\section{References}

Adepoju, A.A., Salau, A.S., and Obayelu, A.E., (2007). The Effects of External Debt Management on Sustainable Economic Growth and Development: Lessons from Nigeria, MPRA, Paper No. 2147.

Ajayi, L.B. and Oke, M.O. (2012). "Effort of External Debt on Economic Growth and Development".

International Journal of Business and Social Science, 3(1), 297-304.

Al-Gifari Hasnu (2015). The effects of government expenditure on economic growth: the case of Malaysia, MPRA No. 71254, 1-15

Ayadi, F.S. and Ayadi, F.O. (2008), "The Impact of External Debt on Economic Growth: A Comparative Study of Nigeria and South Africa". Journal of Sustainable Development in Africa, 10(3), 234-264

Audu I. (2004). The Impact of External Debt on Economic Growth and Public Investment: The Case of Nigeria, African Institute for Economic Development and Planning (IDEP), Dakar.

Barro, R. (1990). Government Spending in a Simple Model of Endogenous Growth. The Journal of Political Economy, 14,103-125.

Copelman, M. and Wermer, A.M. (1996). The Monetary Transmission Mechanism in Mexico. Working Paper, no. 25. Washington, D.C.: Federal Reserve Board.

Fatoumata, K.M. (2017). Impact of Interest Rate on Economic Growth in Nigeria, Pyrex Journal of Business and Finance Management Research, 3(3), 98-111

Fosu A.K. (2007). The External Debt Servicing Constraint and Public Expenditure Composition: Evidence from African Economies, UNU-WIDER. Research Paper No. 2007/36.

Fouladi M. (2010). The Impact of Government Expenditure on GDP, Employment and Private Investment a CGE Model Approach, Iranian Economic Review, 15(27), 53-76

Hakeem B., Rasaki K., and Oyelekan B. (2015). Effects of Inflation Rate on Economic Growth in Nigeria (1986-2014), Developing Country Studies, 5(8), 153

Hammed B.J. (2008). The Impact of Real Gross Domestic Product of Nigeria, Menstar Publisher and Press, Ibadan.

Jelilov G. and Musa M. (2016). The Impact of Government Expenditure on Economic Growth in Nigeria, Sacha Journal of Policy and Strategic Studies, 5(1), 15 - 23

Komain, J. (2007). The Relationship between Government Expenditure and Economic Growth in Turkey. Journal of Economics and Economic Research, 1639-1664.

Malik S., Hayat M.K and Hayat M.U (2010). External Debt and Economic Growth: Empirical Evidence from Pakistan", International Research Journal of Finance and Economics, 44, 88-97.

Mehari, M. and Wondafrash, A. (2008). The Impact of Money Supply on Inflation in Ethiopia. A paper presented at 7th Multidisciplinary Conference in Unity University College, Ethiopia. 
Mohammed, M.M.A. (2005). The Impact of External Debt on Economic Growth: An Empirical Assessment of Sudan: 1978 - 2001, Eastern Social Science Research Review, 21(2), 5366.

Morley, S. A. (1992). On the Effect of Devaluation during Stabilization Programs in LDCs. Review of Economics and Statistics 74(1), 21-27

Ndungu', N.S. (1997). Price and Exchange Rate Dynamics in Kenya: an Empirical Investigation (1970-1993). AERC research Paper, 58.

Nurudeen, A., and Usman, A. (2010). Government Expenditure and Economic Growth in Nigeria, 1970-2008: A Disaggregated Analysis. Business and Economics Journal, 1-11.

Ogunmuyiwa M.S (2011). Does External Debt Promote Economic Growth? Current Research Journal of Economic Theory, 3(1), 29 - 35.

Okoye, L.U., Modebe, N.J., Adedayo, E.O. and Evbuomwan, G.O. (2017). Effect of External Debt on Economic Growth: Evidence from Nigeria, Sustainable Economic Growth, Education Excellence, and Innovation Management through Vision 2020, 4046-4058

Sulaiman, L.A. and Azeez, B.A. (2012), 'Effect of External Debt on Economic Growth of Nigeria".

Journal of Economics and Sustainable Development, 2(8)

Zaman R. and Arslan M. (2014): The Role of External Debt on Economic Growth: Evidence from Pakistan Economy, Journal of Economics and Sustainable Development, 5(24), 140-147 